\title{
Improvement in Wear Properties of a Hypereutectic Aluminium Silicon Alloy with Manganese
}

\author{
Prabhkiran Kaur, D.K. Dwivedi, P.M. Pathak and Sunil Kumar
}

\begin{abstract}
Improvement in wear properties of rare earth Cerium base hypereutectic Aluminium-Silicon alloy with Manganese modification has been reported in this paper. Wear studies were carried out on cast samples of hypereutectic Aluminium-Silicon alloy (Al-Si) with rare earth Cerium oxide $\left(\mathrm{CeO}_{2}\right)$ and Manganese (Mn) modification. Final wear properties of rare earth Cerium oxide and Manganese modified hypereutectic Aluminium Silicon alloy were compared with the values of author's previous work on rare earth Cerium oxide modified hypereutectic Aluminium Silicon alloy and hypereutectic Aluminium Silicon base alloy. Rare earth Cerium oxide and Manganese modification in hypereutectic Aluminium Silicon base alloy reduced the wear rates as compared to rare earth Cerium oxide modified hypereutectic Aluminium Silicon alloy and hypereutectic Aluminium Silicon base alloy. A comparison of wear rates at same velocity, load and sliding distance was made between above three different conditions and it was observed that rare earth Cerium oxide and Manganese modified alloy performed with least wear rates. Wear rates for rare earth Cerium oxide and Manganese modified hypereutectic Aluminium Silicon alloy was 6.36 times lesser than wear rate of hypereutectic Aluminium Silicon base alloy and was 2.97 times lesser than rare earth Cerium oxide modified hypereutectic Aluminium Silicon alloy. Wear rates were also calculated for rare earth Cerium oxide and Manganese modified hypereutectic Aluminium Silicon alloy at various velocities ranging from 0.2 $\mathrm{m} / \mathrm{s}$ to $1.0 \mathrm{~m} / \mathrm{s}$ at an equal interval of $0.2 \mathrm{~m} / \mathrm{s}$. It was noticed that minimum wear occurred at $1.0 \mathrm{~m} / \mathrm{s}$ velocity and maximum at $0.2 \mathrm{~m} / \mathrm{s}$ velocity. Further, scanning electron micrographs (SEM) of worn surfaces and wear debris of rare earth Cerium oxide and Manganese modified hypereutectic Aluminium Silicon alloy were compared at low velocity $(0.2 \mathrm{~m} / \mathrm{s})$ and high velocity $(1.0 \mathrm{~m} / \mathrm{s})$ conditions at constant load $(30 \mathrm{~N})$ and sliding distance $(500 \mathrm{~m})$. It was observed that worn surface and wear debris of rare earth Cerium oxide and Manganese modified hypereutectic Aluminium Silicon alloy, showed mild oxidative wear irrespective of lower velocity.
\end{abstract}

Keywords--- Aluminium Silicon Alloy, Manganese, Cerium Oxide, Wear, Debris and Rare Earth.

Prabhkiran Kaur, Research Scholar, Mechanical and Industrial Engineering Department, I.I.T Roorkee, Uttarakhand, India. E-mail: pkiran_vora@yahoo.co.in

D.K. Dwivedi, Associate Professor, Mechanical and Industrial Engineering Department, I.I.T Roorkee, Uttarakhand, India.

P.M. Pathak, Associate Professor, Mechanical and Industrial Engineering Department, I.I.T Roorkee, Uttarakhand, India.

Sunil Kumar, Assistant Professor, Mechanical Engineering Department, SLIET, Longowal, Sangrur, Punjab, India. E-mail: sunil_thappa@yahoo.com

DOI: 10.9756/BIJIEMS.6043

\section{INTRODUCTION}

$\mathrm{H}$ YPEREUTECTIC Aluminium Silicon alloys are widely used in military, automobile, aerospace and electronic industries because of properties like excellent wear, corrosion resistance, low density and coefficient of thermal expansion, good strength and castability [1]. The microstructure of hypereutectic Al-Si alloys is composed of primary silicon particles and eutectic structure of alpha $(\alpha)-\mathrm{Al}$ and Si. The wear resistance and mechanical performance of hypereutectic $\mathrm{Al}-\mathrm{Si}$ alloys is influenced by the formation of primary $\mathrm{Si}$ particles and segregation of eutectic Si at grain boundaries. Presence of coarse blocky shape primary silicon particles reduces mechanical properties such as tensile strength and ductility of these alloys. This greatly restricts the application of hypereutectic aluminum silicon alloys in many areas. Refinement of primary silicon particles is an effective way to overcome these limitations in hypereutectic Al-Si alloys [2]. A lot of work has been reported on die casting and mechanical stir casting processes $[3,4]$ for improving the mechanical and wear performance of these alloys. Refinement of primary silicon particles in large castings of these alloys by addition of Phosphorus (P) based compounds imposes difficulties like evaporation/oxidation of Phosphorous which is harmful for the manpower. Therefore, refinement by using Phosphorous is not assumed a very effective method. It has been reported that rare earth element Cerium oxide $\left(\mathrm{CeO}_{2}\right)$ helps to modify the morphology of primary and eutectic silicon particles [5, 6]. Cerium helps to reduce the size of primary silicon particles and beta phase iron needles. Small size primary silicon particles are useful in increasing the strength of a hypereutectic $\mathrm{Al} \mathrm{Si}$ alloy but beta phase iron needles although in reduced size are harmful as they provide easy path for crack nucleation and growth. So, introduction of another element like Manganese helps to neutralize the formation of beta needles in the hypereutectic and hypoeutectic alloys as mentioned in literature [7, 8]. The effect of Cerium oxide on the hypereutectic Aluminium Silicon alloys has already been established using advanced manufacturing processes [9]. Further, the effect of Cerium oxide on the wear performance using different loads and velocities has also been presented in the literature [10]. But the effect of Cerium oxide along with Manganese at different velocities has not been studied so far. The present work is therefore an attempt to study the wear performance of hypereutectic Aluminium Silicon alloy modified with rare earth Cerium oxide and Manganese under low, medium and high velocities ranging from $0.2 \mathrm{~m} / \mathrm{s}$ to 1.0 $\mathrm{m} / \mathrm{s}$ at an equal interval of $0.2 \mathrm{~m} / \mathrm{s}$ at constant load $(30 \mathrm{~N})$ and sliding distance $(500 \mathrm{~m})$ conditions. Further, to compare wear 
rates of rare earth Cerium oxide and Manganese modified hypereutectic Al-Si alloy with Cerium oxide modified Al-Si alloy and hypereutectic Al-Si base alloy evaluated in previous work [10].

\section{EXPERIMENTAL PROCEDURE}

This section presents the experimental procedure followed for the development of casting and standard procedure followed for wear testing of the present alloy under different velocity, constant load and sliding distance conditions.

\section{A. Development of Casting}

The experimental alloy called hypereutectic Al-16 (wt\%) $\mathrm{Si}$ alloy was prepared in an induction furnace at $900^{\circ}-950^{\circ} \mathrm{C}$. Graphite crucibles were used for melting and casting, where casting process was done with conventional green sand mould casting technique. Cerium oxide - $0.2(\mathrm{wt} \%)$ was introduced to the prepared hypereutectic Al-Si alloy at about $850^{\circ}-900^{\circ} \mathrm{C}$ in separate crucible and kept there for an hour to provide the proper mixing of the alloy and was then cast. Similarly, Manganese at $0.4(\mathrm{wt} \%)$ was added to Cerium oxide modified hypereutectic $\mathrm{Al}-\mathrm{Si}$ alloy in separate crucible and kept at $800^{\circ}$ $-900^{\circ} \mathrm{C}$ for proper mixing and then was cast in green sand moulds. Samples of Cerium oxide and manganese modified hypereutectic Al-Si alloy were cast and taken for wear testing.

\section{B. Wear testing of Alloy}

Wear testing was done under dry sliding conditions on a reciprocating wear test rig. The apparatus used for wear testing was made under ASTM standard G-133-05 and wear testing of the alloy was also done following the same standards. Size of the wear pins for testing was $6 \mathrm{~mm}$ diameter and $30 \mathrm{~mm}$ length. A grey cast iron plate was used against the wear pins whose average surface roughness (Ra) was $235 \mathrm{~nm}$. Wear testing was done at a constant sliding distance of $500 \mathrm{~m}$ and a constant load of $30 \mathrm{~N}$ at sliding velocities varying from $0.2 \mathrm{~m} / \mathrm{s}$ to $1.0 \mathrm{~m} / \mathrm{s}$ at an equal interval of $0.2 \mathrm{~m} / \mathrm{s}$.

\section{Scanning Electron Micrograph (SEM)}

Specimens for SEM were prepared by cutting off worn surfaces of $\mathrm{CeO}_{2}$ and Manganese modified hypereutectic $\mathrm{Al}-\mathrm{Si}$ alloy at different velocities. Specimens were mounted inside the Scanning electron microscope and then micrographs were taken at high magnification (250X). Wear debris were directly put on the mount and then micrographs were taken.

\section{RESULTS AND DISCUSSION}

Earlier, many researchers have done studies for determining the wear rates of alloys in dry sliding adhesive wear under reciprocating conditions [11]. Author has already established in her earlier work [10] that improvement of wear properties can be achieved by adding Cerium oxide to a hypereutectic Al-Si alloy. Present work is an extension of the previous work by adding $\mathrm{Mn}$ to the hypereutectic alloy which has not been done earlier as per literature [12]. So in the present study, a comparison of wear rates of hypereutectic AlSi base alloy [10] and Cerium oxide modified alloy with Cerium oxide and Mn modified alloy has been done to establish that $\mathrm{Mn}$ helps to reduce the wear rates of Cerium oxide modified hypereutectic Al-Si alloy. Wear studies were done at a constant sliding distance of $500 \mathrm{~m}$, a constant load of $30 \mathrm{~N}$ and sliding velocity $0.2 \mathrm{~m} / \mathrm{s}$ to $1.0 \mathrm{~m} / \mathrm{s}$ at an interval of $0.2 \mathrm{~m} / \mathrm{s}$ (Figure 1). It can be observed from Figure 1 that $\mathrm{Mn}$ modification had reduced wear rate of Cerium oxide modified hypereutectic $\mathrm{Al}-\mathrm{Si}$ alloy as compared to wear rates of only Cerium oxide modified hypereutectic Al-Si alloy and hypereutectic Al-Si base alloy.

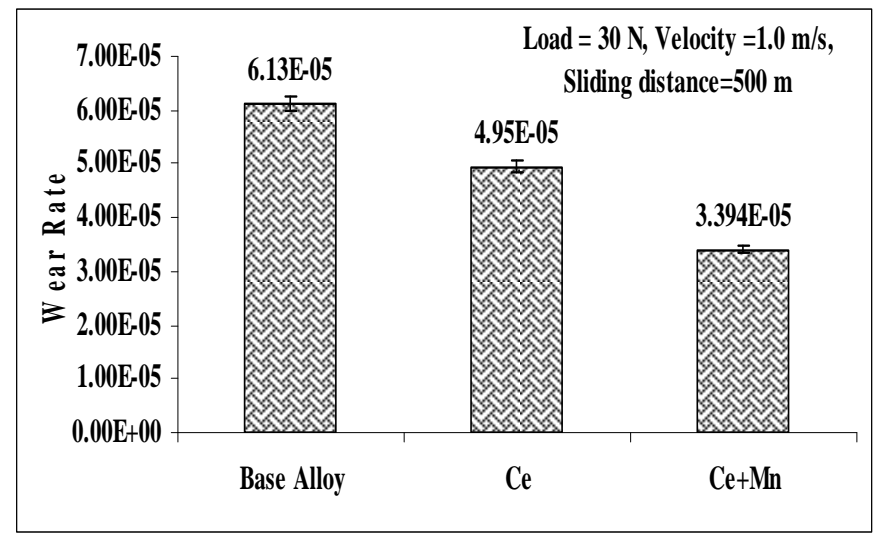

Figure 1: Comparison of Wear Rates of Hypereutectic Base Alloy in as Cast Condition (Base Alloy), Cerium Oxide Modified Condition (Ce) and Cerium Oxide and Mn Modified Condition $(\mathrm{Ce}+\mathrm{Mn})$ at Constant Load $(30 \mathrm{~N})$, Constant Velocity $(1.0 \mathrm{~m} / \mathrm{s})$ and Constant Sliding Distance of $500 \mathrm{~m}$

Wear rate of Cerium oxide modified hypereutectic Al-Si alloy was 2.97 times lesser than the wear rate of Cerium oxide and Mn modified hypereutectic Al-Si base alloy and wear rate of base alloy is 6.36 times lesser than the wear rate of Cerium oxide and $\mathrm{Mn}$ modified hypereutectic Al-Si alloy. Thus, Manganese modification to rare earth Cerium oxide helps in improving the wear resistance of hypereutectic Al-Si alloy by increasing hardness [11] and as per Archard law [13] hardness is inversely proportional to wear rate. Figure 2 shows the wear rates of Cerium oxide and $\mathrm{Mn}$ modified hypereutectic $\mathrm{Al}-\mathrm{Si}$ alloy at various sliding velocities ranging from $0.2 \mathrm{~m} / \mathrm{s}$ to 1.0 $\mathrm{m} / \mathrm{s}$ at an equal interval of $0.2 \mathrm{~m} / \mathrm{s}$.

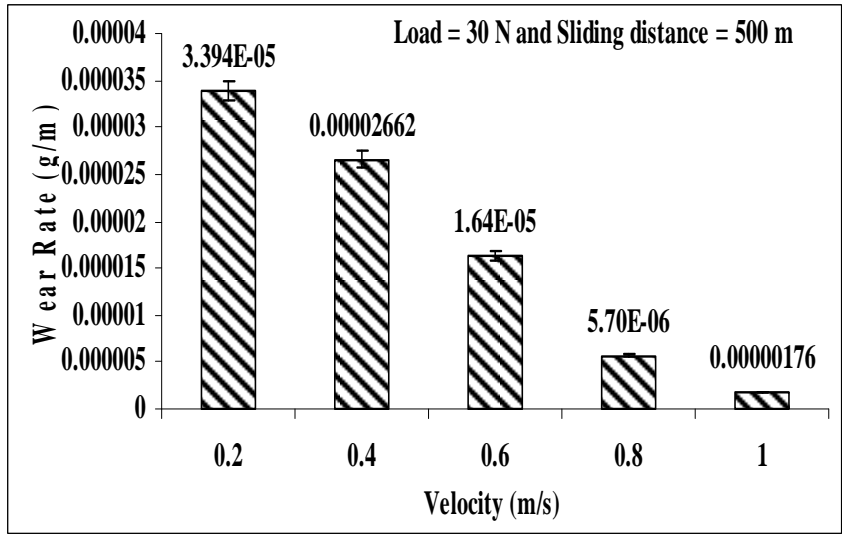

Figure 2: Wear Rate of Cerium Oxide and Manganese Modified (Ce+Mn) Hypereutectic Al-Si Alloy at varying Sliding Velocities from $0.2 \mathrm{~m} / \mathrm{s}$ to $1.0 \mathrm{~m} / \mathrm{s}$ at an Equal Interval of $0.2 \mathrm{~m} / \mathrm{s}$ and Constant Load of $30 \mathrm{~N}$ and Sliding Distance of $500 \mathrm{~m}$ 
For the present alloy system wear rate was more at low velocity due to more surface to surface contact and wear rate was lesser at higher velocity due to less surface to surface contact. It can be observed that wear rate of Cerium oxide and Manganese modified hypereutectic Al-Si alloy at $0.6 \mathrm{~m} / \mathrm{s}$ sliding velocity $(1.64 \mathrm{E}-05 \mathrm{~g} / \mathrm{m})$ was slightly more than the wear rate of hypereutectic Al-Si base alloy at $1.0 \mathrm{~m} / \mathrm{s}(1.12 \mathrm{E}-$ 05). Similarly, wear rate of Cerium oxide and Manganese modified hypereutectic Al-Si alloy at a sliding velocity of 0.8 $\mathrm{m} / \mathrm{s}(5.70 \mathrm{E}-06)$ was slightly more than the wear rate of Cerium oxide modified hypereutectic Al-Si alloy at $1.0 \mathrm{~m} / \mathrm{s}$ (5.24E06). This signifies that Cerium and Manganese modification of hypereutectic $\mathrm{Al}-\mathrm{Si}$ alloy reduces the wear rates even at lower velocities and improves wear resistance. Also, wear rates of Cerium oxide and $\mathrm{Mn}$ modified hypereutectic Al-Si alloy at lower velocity $(0.6 \mathrm{~m} / \mathrm{s})$ was just slightly above (fifth decimal) than the wear rates of hypereutectic Al-Si base alloy at higher velocity $(1.0 \mathrm{~m} / \mathrm{s})$ and wear rate of Cerium oxide and $\mathrm{Mn}$ modified hypereutectic Al-Si alloy at lower velocity $(0.8 \mathrm{~m} / \mathrm{s})$ was slightly above than the wear rate of Cerium oxide modified alloy $(1.0 \mathrm{~m} / \mathrm{s})$ at higher velocity. So, hypereutectic Al-Si alloy can be used at lower velocities with lesser wear rates. Rare earth Cerium oxide is known to reduce the size of primary silicon particles and beta iron phases which are present in hypereutectic Al-Si alloy. Primary silicon particles increases strength of the alloy and improve wear resistance but beta iron phases reduces strength as they provide easy path for nucleation and growth of defects. These phases although in reduced size harm the wear properties and increase wear rates. $\mathrm{Mn}$ is reported to neutralize the effect of beta iron phases. So, Mn when added to Cerium oxide further enhanced the wear properties and improved wear resistance by reduction in wear rates.

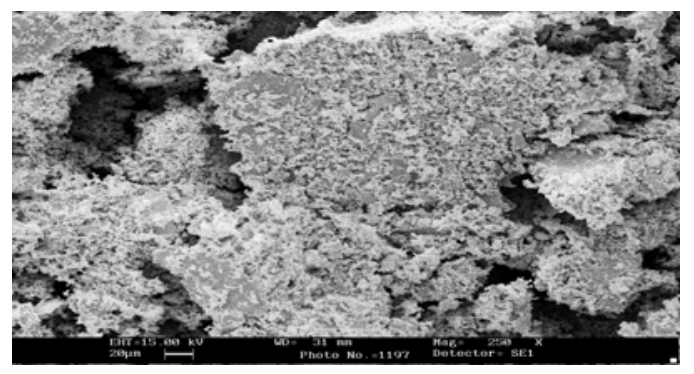

(a)

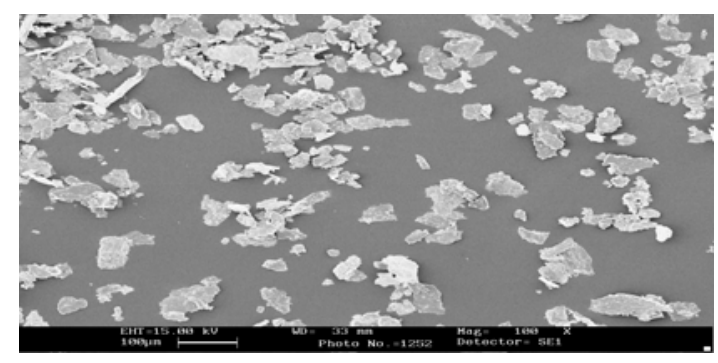

(b)

Figure 3: Comparison of SEM of Wear Debris of Cerium and Manganese Modified Hypereutectic Al-Si Alloy at High Magnification (500X) a) at $0.2 \mathrm{~m} / \mathrm{s}$ and b) at $1.0 \mathrm{~m} / \mathrm{s}$ Velocity, Constant Load of $30 \mathrm{~N}$ and Constant Sliding Distance of $500 \mathrm{~m}$
Figure 3a and $\mathrm{b}$ shows SEM of wear debris of Cerium and Manganese modified hypereutectic Al-Si alloy at high magnification $(500 \mathrm{X})$ a) at $0.2 \mathrm{~m} / \mathrm{s}$ and b) at $1.0 \mathrm{~m} / \mathrm{s}$ velocity and constant load of $30 \mathrm{~N}$ and constant sliding distance of $500 \mathrm{~m}$. It can be observed in Figure 3a that wear debris was fine at low sliding velocity $(0.2 \mathrm{~m} / \mathrm{s})$ due to low speed and wear is of oxidative type. There were few large size particles seen that were delaminated from the wear surface during the wear process but mostly the particles were of powdery form and small size. At high velocity $(1.0 \mathrm{~m} / \mathrm{s})$ the debris particles were of small size and the quantity was lesser due to less surface to surface contact and the wear was mild oxidative type. It means that the Mn addition to Cerium oxide modified hypereutectic Al-Si alloy improved the wear resistance and reduced the wear rates even at lower velocities $(0.2 \mathrm{~m} / \mathrm{s})$.

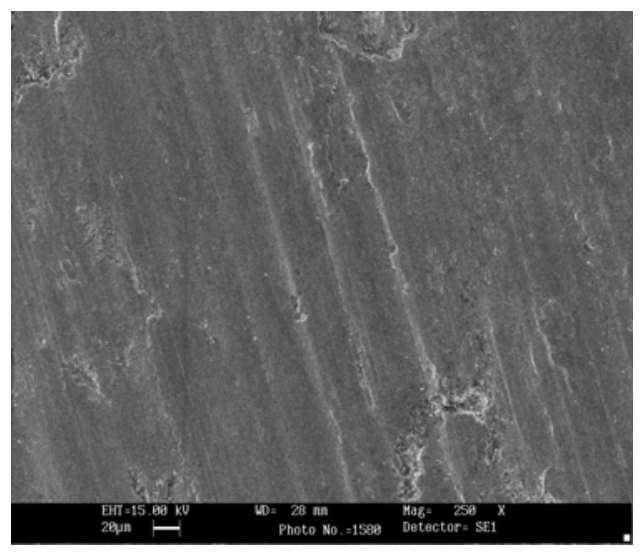

(a)

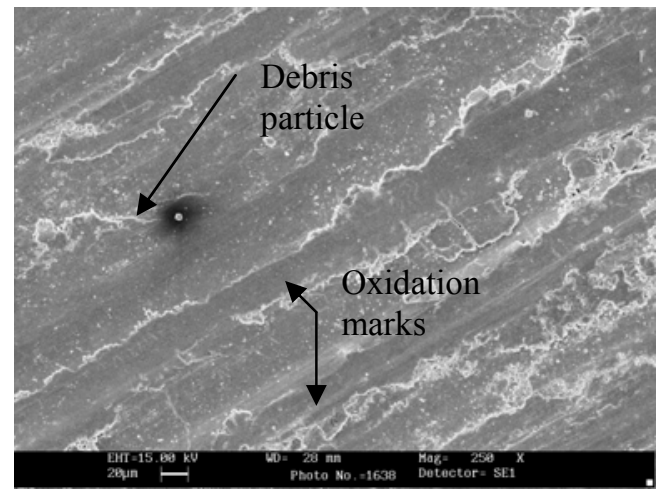

Figure 4: Comparison of Worn Surface of Cerium and Manganese Modified Hypereutectic Al-Si Alloy a) at Low velocity $(0.2 \mathrm{~m} / \mathrm{s})$ b) at High Velocity $(1.0 \mathrm{~m} / \mathrm{s})$.

Figure $4 \mathrm{a}$ and $\mathrm{b}$ shows the worn surface of Cerium and Manganese modified hypereutectic Al-Si alloy a) at low velocity $(0.2 \mathrm{~m} / \mathrm{s})$ b) at high velocity $(1.0 \mathrm{~m} / \mathrm{s})$. Figure $4 \mathrm{a}$ shows the worn surfaces of the Cerium and Mn modified hypereutectic Al-Si alloy and it can be observed that the alloy at low velocity mild oxidation wear marks are there. Figure $4 \mathrm{~b}$ shows the worn surface of Cerium and $\mathrm{Mn}$ modified hypereutectic Al-Si alloy at high velocity and again worn surface has mainly oxidation marks and one debris particle due to delamination. 


\section{CONCLUSION}

The following conclusions were drawn from the above investigation

- Manganese modification to Cerium oxide modified hypereutectic Al-Si alloy reduces the wear rate.

- Wear rates of Cerium oxide and Mn modified hypereutectic Al-Si alloy at lower velocities were slightly above the wear rates of hypereutectic Al-Si base alloy and Cerium oxide modified Al-Si alloy at higher velocities. Thus alloy modified with $\mathrm{Mn}$ performs better at lower velocities.

- Wear debris of Cerium and Manganese modified hypereutectic Al-Si alloy at low velocity $(0.2 \mathrm{~m} / \mathrm{s})$ and high velocity $(1.0 \mathrm{~m} / \mathrm{s})$ showed mild wear.

- Worn surface of Cerium and Manganese modified hypereutectic Al-Si alloy at low velocity $(0.2 \mathrm{~m} / \mathrm{s})$ and high velocity $(1.0 \mathrm{~m} / \mathrm{s})$ showed mild wear.

\section{REFERENCES}

[1] Elwin L. Rooy, "Aluminium and Aluminium alloys", Aluminium Company of America, 2002.

[2] S. Nafisi, D. Emadi, M.T. Shehata and R. Ghomashchi, Effects of electromagnetic stirring and superheat on the microstructural characteristics of Al-Si-Fe alloy, Materials Science and Engineering A, 432, 71-83, 2006.

[3] Z. Fan, Semisolid metal processing, International Materials Review, 47(2), 1-37, 2002.

[4] Atkinson Helen, Current status of semi-solid processing of metallic materials, In: Advances in material forming, Esaform 10 years on, ISBN-13, 978-287-72142-7, Springer-Verlag France, Paris, 81-98, 2007.

[5] D. H. Xiao, J. N. Wang and D. Y. Ding, Effect of rare earth Ce addition on the microstructure and mechanical properties of an $\mathrm{Al}-\mathrm{Cu}-\mathrm{Mg}-\mathrm{Ag}$ alloy, Journal of Alloys and Compounds 352, 84-88, 2003.

[6] H. Zhang, H. Duan, G. Shao, Modification mechanism of cerium on the Al-18Si alloy, Rare Metals, 25(1), 11-15, 2006.

[7] Prabhkiran kaur, Improving microstructure, mechanical properties and adhesive wear behaviour of hypoeutectic Al-Si alloy by electromagnetic stirring, International Journal of Engineering Science and Technology (IJEST),Vol. 3 No.10, pp. 7525-7529, 2011.

[8] V. Abouei, H. Saghafian, S. G. Shabestari, M. Zarghami, Effect of Ferich intermetallics on the wear behaviour of eutectic Al-Si piston alloy (LM13), Materials and Design, 31, pp. 3518-3524, 2010.

[9] Prabhkiran Kaur, D. K. Dwivedi and P.M. Pathak, Effects of electromagnetic stirring and rare earth compounds on the microstructure and mechanical properties of hypereutectic $\mathrm{Al}-\mathrm{Si}$ alloys, International Journal of Advanced Manufacturing Technology, vol. 63, issue 1-4, pp 415-420, 2012.

[10] Prabhkiran Kaur, Dheerendra Kumar Dwivedi, Pushpraj Mani Pathak and Sergio Haro Rodriguez, The effect of electromagnetic stirring and cerium addition on dry sliding reciprocating wear $\mathrm{Al}-\mathrm{Si}$ alloy, Proceedings of Institute of Mechanical Engineers Part J: Journal of Engineering Tribology, 226(30), 251-258, 2011.

[11] D. K.Dwivedi, Adhesive wear behavior of cast aluminium-silicon alloys: Overview, Materials and Design, 31, pp. 2517-2531, 2010.

[12] X. Fang, G. Shao, Y. Q. Liu and Z. Fan, Effects of intensive forced melt convection on mechanical properties of Fe containing Al-Si based alloy, Material Science and Engineering A, 445-446, pp. 65-72, 2007.

[13] Ernest Rabinowicz, "Friction and Wear of materials" John Wiley and Sons, USA, 1975. 